\title{
Inhibition of $\alpha$-glucosidase activity, metals content, and phytochemical profiling of Andrographis paniculata from different geographical origins based on FTIR and UHPLC-Q-Orbitrap HRMS metabolomics
}

\author{
MOHAMAD RAFI ${ }^{1,2,3,}$, DEWI ANGGRAINI SEPTANINGSIH ${ }^{2,3}$, ALFI HUDATUL KAROMAH ${ }^{1}$, LUKMAN $^{4}$, \\ BAMBANG PRAJOGO ${ }^{4}$, MUHAMMAD BACHRI AMRAN ${ }^{5}$, ABDUL ROHMAN ${ }^{6}$ \\ ${ }^{1}$ Department of Chemistry, Faculty of Mathematics and Natural Sciences, Institut Pertanian Bogor. Jl. Tanjung Kampus IPB Dramaga, Bogor 16680, \\ West Java, Indonesia, "email: mra @apps.ipb.ac.id \\ ${ }^{2}$ Tropical Biopharmaca Research Center, Institute of Research and Community Services, Institut Pertanian Bogor. Jl. Taman Kencana No. 3 Kampus IPB \\ Taman Kencana, Bogor 16128, West Java, Indonesia \\ ${ }^{3}$ Advance Research Laboratory, Institut of Research and Community and Community Services, Institut Pertanian Bogor. J1. Palem Raya Kampus IPB \\ Dramaga, Bogor 16880, West Java, Indonesia \\ ${ }^{4}$ Department of Pharmacognosy and Phytochemistry, Faculty of Pharmacy, Universitas Airlangga. Jl. Mulyorejo, Kampus C Unair, Surabaya 60286, East \\ Java, Indonesia \\ ${ }^{5}$ Analytical Chemistry Research Group, Institut Teknologi Bandung. Jl. Ganesha No. 10, Bandung 40132, West Java, Indonesia \\ ${ }^{6}$ Department of Pharmaceutical Chemistry, Faculty of Pharmacy, Universitas Gadjah Mada. Jl. Kaliuarang Km 4.5, Sekip Utara, Sleman 55281, \\ Yogyakarta, Indonesia
}

Manuscript received: 19 January 2021. Revision accepted: 27 February 2021.

\begin{abstract}
Rafi M, Septaningsih DA, Karomah AH, Lukman, Prajogo B, Amran MB, Rohman A. 2021. Inhibition of $\alpha$-glucosidase activity, metals content, and phytochemical profiling of Andrographis paniculata from different geographical origins based on FTIR and UHPLC-Q-Orbitrap HRMS metabolomics. Biodiversitas 22: 1535-1542. Ensuring consistency of quality, safety, and efficacy of herbal medicines from raw materials to finished products is important because of the variability in medicinal plants' active components. One of the plants that have been used as an antidiabetic herbal medicine is A. paniculata. This study aims to determine $\alpha$-glucosidase inhibitory activity, the content of several metals, FTIR spectrum profile, and putative identification of A. paniculata metabolites using UHPLC-QOrbitrap HRMS from different geographical origin. We found that ethanol extract of A. paniculata gave higher inhibition of $\alpha$ glucosidase activity compared to water extract. Eight metals were determined using FAAS and FAES, and calcium showed the highest content in all A. paniculata samples. FTIR spectra of $A$. paniculata showed a similar profile and only differed in the absorbance. We detected the presence of $\mathrm{OH}, \mathrm{C}=\mathrm{O}, \mathrm{C}=\mathrm{C}$ aromatic, and $\mathrm{C}-\mathrm{O}$ functional groups in A. paniculata extract. About 32 metabolites were putatively identified in A. paniculata, mainly from phenolic and diterpene lactones class compounds based on UHPLC-Q-Orbitrap HRMS. Using a combination of FTIR spectra and peak area from 32 identified peaks, we can clustered A. paniculata based on its geographical origin. Based on the result obtained, the geographical origin of A. paniculata affected the metals and metabolites composition and level, resulting in different levels of $\alpha$-glucosidase inhibitory activity.
\end{abstract}

Keywords: Andrographis paniculata, geographical origins, $\alpha$-glucosidase, metabolomics, FTIR, UHPLC-Q-Orbitrap HRMS

\section{INTRODUCTION}

The raw material for medicinal plants needs quality testing to ensure consistency of quality, safety, and efficacy of herbal medicines because medicinal plants have large variability in the content of their active components. Genotypic factors, extracting solvents, harvesting time, post-harvest process, and season can affect bioactive compounds' composition and concentration in medicinal plants (Zantar et al. 2015). The growth location is also very influential on the active compounds contained therein (Khattak and Rahman 2015). A species of the same medicinal plant from different growing locations will contain different metabolite compounds due to differences in environmental conditions, such as temperature, humidity, the water content in the soil, and salinity (Sampaio et al. 2016; Borges et al. 2017). Therefore, research on the effect of different growing locations is fundamental to determine the quality of herbal medicinal raw materials.

The evaluation of the quality of herbal medicinal raw materials is currently determined by measuring the concentration of one or a group of chemical components that have certain pharmacological activities in the constituent medicinal plants (Brinckmann 2013). Quality control of medicinal plants can be carried out using a metabolomics approach to obtain information about the chemical components that can be detected to evaluate their raw materials. There is a possibility that a medicinal plant may work synergistically (van der Kooy et al. 2009). Several metabolomic approaches can be used to evaluate the quality of medicinal plants, such as metabolite profiling and fingerprint analysis (Awin et al. 2016; Umar et al. 2021; Aziz et al. 2020). Spectroscopic techniques like FTIR is widely used for fingerprint analysis because easy to use, fast, and cheap (Bunaciu et al. 2011). UHPLC-QOrbitrap HRMS is an attractive and efficient instrument in 
metabolomics analysis because highly selective and sensitive and able to accurately identify the metabolite contain in plant sample (Xiao et al. 2012)

Andrographis paniculata was chosen as the sample because widely used in herbal medicinal products. $A$. paniculata has several biological activities, one of which is antidiabetic (Aneesh et al. 2018). This biological activity is caused by the bioactive metabolites contained therein. The main metabolite compounds contained in A. paniculata are the diterpene lactone and flavonoid groups. Besides that, the metal composition and content in A. paniculata is also responsible for its medicinal properties and its toxicity (Mythili et al. 2011). Several previous studies have reported the metal content (Mythili et al. 2011) and metabolite profile of A. paniculata (Chua et al. 2013; Song et al. 2013; Yusof et al. 2015; Aneesh et al. 2018; Maria et al. 2018; Tajidin et al. 2019; Rafi et al. 2020a; Rafi et al. 2020b). Those studies only reported the metabolite profile of A. paniculata and the differences in the composition and concentration of metabolites because of different plant parts and age, harvest time, mature and young leaves, and solvent extraction. However, no one has reported the influence of growth location especially in Indonesia associated with the metabolite profile and biological activity of $A$. paniculata. Therefore, this study aims to determine the $\alpha$-glucosidase inhibitory activity, metal content, differences in the FTIR spectra profile, and putative identification of metabolites present in $A$. paniculata extract from several regions in Java island, Indonesia using UHPLC-Q-Orbitrap HRMS.

\section{MATERIALS AND METHODS}

\section{Sampling location of Andrographis paniculata}

The leaves and stems of A. paniculata were collected in April 2019 from several locations in Java island, Indonesia, as shown in Table 1. The plants used in this research were 3 months old. The sample was identified by an expert from Tropical Biopharmaca Research Center (TropBRC), IPB University, Bogor, Indonesia. A voucher specimen from all samples was stored at TropBRC, IPB University, Bogor, Indonesia.

Table 1. Location of collected sample

\begin{tabular}{ll}
\hline Code of sample & Location of sample \\
\hline AP1 & Dramaga, Bogor, West Java \\
AP2 & Nagrak, Sukabumi, West Java \\
AP3 & Bayumanik, Semarang, Central Java \\
AP4 & Karangpandan, Karanganyar, Central Java \\
AP5 & Kejayan, Pasuruan, East Java \\
AP6 & Batu, East Java \\
AP7 & Poncol, Magetan, East Java \\
\hline
\end{tabular}


Avanta AAS, GBC Scientific Company, Victoria, Australia) in A. paniculata sample.

\section{Measurement of FTIR spectra}

All of the A. paniculata samples were measured with a Thermo Scientific Nicolet iS10 FTIR spectrophotometer equipped with OMNIC and TQ Analyst software (Thermo Fisher Scientific. Inc, Madison, USA). The sample measurement technique using attenuated total reflectance (ATR) with the extract was placed on the ATR crystal. FTIR spectra were recorded at wavenumbers 4000 to 650 $\mathrm{cm}^{-1}$, with scans 32 and resolution about $4 \mathrm{~cm}^{-1}$. Measurements were made 2 times and recorded as absorbance data. After scanning, the ATR crystals were cleaned with ethanol and acetone two times. At each sample measurement, a background measurement is carried out to avoid spectrum variations between times. Background measurements are carried out by measuring the IR absorption without the presence of a sample.

\section{Separation and putative identification of metabolites using UHPLC-Q-Orbitrap HRMS}

A. paniculata powder was extracted using methanol with a ratio between sample and solvent of about 1:10 for 30 minutes at room temperature. Separation of $A$. paniculata metabolites was performed according to the procedure described by Rafi et al. (2021) using Vanquish Flex UHPLC-Q Exactive Plus Orbitrap-High Resolution Mass Spectrometer with Accucore ${ }^{T M}$ phenyl hexyl $(100 \mathrm{x}$ $2.1 \mathrm{~mm}, 2.6 \mu \mathrm{m})$ as separation column. We used mobile phase $0.1 \%$ formic acid in water (A) and $0.1 \%$ formic acid in acetonitrile (B) with gradient elution as follow: 0.00$1.73 \mathrm{~min}(30-40 \% \mathrm{~B}) ; 1.73-6.93 \mathrm{~min}(40-75 \% \mathrm{~B}) ; 6.93-7.80$ $\min (75-100 \% \mathrm{~B}) ; 7.80-8.23(100-30 \% \mathrm{~B}), 8.23-13.00 \mathrm{~min}$ $(30 \% \mathrm{~B})$. The flow rate was maintained at $0.2 \mathrm{~mL} / \mathrm{min}$ and an injection volume of about $2 \mu \mathrm{L}$. Other conditions for UHPLC-Q-Orbitrap HRMS analysis were as followed: the source of MS ionization used was ESI (+) with Q-Orbitrap mass analyzer with $\mathrm{m} / \mathrm{z}$ range from $133-2000 \mathrm{~m} / \mathrm{z}$. The collision energy used for fragmentation was 18, 35, and 53 $\mathrm{eV}$. Spray voltage used about $3.8 \mathrm{kV}$, the capillary temperature is $320^{\circ} \mathrm{C}$, sheath gas, and auxiliary gas flow rates are 15 and $3 \mathrm{~mL} / \mathrm{min}$, respectively. We used scan type full MS/dd $\mathrm{MS}^{2}$ for positive ion mode.

Putative identification of metabolites detected in $A$. paniculata extracts was performed using mass spectrum obtained from UHPLC-Q-Orbitrap HRMS and processed by Compound Discoverer version 2.2. We employed an inhouse database collected from various scientific articles related to $A$. paniculata to identify the metabolites. In the software, we performed select spectra, align retention time, detect unknown compounds, group of unknown compounds, predict compositions, search mass list, fill gaps, normalized areas, and marked background compounds for putative identification of $A$. paniculata metabolites.

\section{Data analysis}

Distinguishing of $A$. paniculata, according to geographical origin, was performed using principal component analysis (PCA). We used the Unscrambler X version 10.1 software (CAMO, Oslo, Norway) for running PCA. Two PCA models were made with absorbance data from the IR spectra of the sample in the region 4000-650 $\mathrm{cm}^{-1}$ and relative peak area of 32 as the variables from UHPLC-Q-Orbitrap HRMS chromatogram.. Before subjected to PCA, we preprocessed FTIR spectra using baseline correction and standard normal variate (SNV).

\section{RESULTS AND DISCUSSION}

\section{Extraction yield and inhibition of $\alpha$-glucosidase of Andrographis paniculata extracts}

In this study, sample extraction was carried out using maceration with ethanol p.a. solvent and decoction with distilled water. The yield extract and inhibition of $\alpha$ glucosidase is shown in Table 2. In general, the highest yield was shown by the ethanolic extract compared to the water extract of $A$. paniculata from different locations of growth. The yield of extracts in each location was different because of the environmental condition. The highest yields of ethanol and water extracts were obtained from $A$. paniculata obtained from Dramaga, Bogor (AP1), and $A$. paniculata collected from Batu, Malang (AP6) showed the lowest yield.

Each extract's inhibitory strength was expressed by a concentration value capable of inhibiting enzyme activity as much as $50 \%\left(\mathrm{IC}_{50}\right)$. The lower the $\mathrm{IC}_{50}$ value, the more active the extract is. The results showed that the ethanol extract was more active than the water extract. AP1 ethanol extract had the strongest activity. The solubility of andrographolide, which can inhibit $\alpha$-glucosidase, is thought to be the leading cause of this difference. This is because andrographolide is easily dissolved in ethanol.

\section{Metals concentration in Andrographis paniculata}

Eight metals were analyzed in A. paniculata samples, namely $\mathrm{Na}, \mathrm{K}, \mathrm{Ca}, \mathrm{Mg}, \mathrm{Zn}, \mathrm{Fe}, \mathrm{Cd}$, and $\mathrm{Pb}$. The analysis results of several alkali metals, alkaline earth, transition metals, and precious metals can be seen in Figure 1. The analysis results show that all metals are contained in each sample. However, each sample contains metals with different concentrations. Ca was detected with the highest content in all regions compared to other metals. The $\mathrm{Ca}$ and Fe content of AP3 and AP5 are quite different compared to the other 5 regions. The metal $\mathrm{Na}, \mathrm{K}, \mathrm{Mg}$, and $\mathrm{Zn}$ content is relatively close to its value whereas $\mathrm{Cu}$ and $\mathrm{Cd}$ were not found to be present in all regions. This indicates the influence of the growing location on the metal concentration contained in A. paniculata. Based on these data, calcium is the metal with the highest concentration contained in all samples.

\section{FTIR spectra of Andrographis paniculata}

The FTIR spectrum is used to identify functional groups present in the metabolites present in a sample. The FTIR spectrum pattern of $A$. paniculata from various sampling locations will show very similar patterns because the metabolites' composition in one species will undoubtedly be relatively the same, as shown in Figure 2. 
The difference in absorption bands seen from each sample of A. paniculata from various growth locations can be observed at the wave number $1500-1200 \mathrm{~cm}^{-1}$, the fingerprint area. This difference indicates the diversity of metabolites extracted from each sample. Also, different absorbance intensities in several absorption bands in each extract indicated a difference in the metabolites' levels. The difference in the number of these metabolites affects biological activities such as inhibition of the enzyme $\alpha$ glucosidase, which also has different values, as shown in Table 2.

Table 3 showed the identified functional groups present in A. paniculata extracts. The absorption band of stretching vibration around $3300 \mathrm{~cm}^{-1}$ was identified as $\mathrm{OH}$ groups and detected in all $A$. paniculata samples. Other functional groups detected in all samples were $\mathrm{C}=\mathrm{O}$ (stretching vibration), $\mathrm{C}=\mathrm{C}$ aromatic (stretching vibration), and $\mathrm{C}-\mathrm{O}$ for $\mathrm{C}-\mathrm{OH}$ (bending vibration) at wavenumber $1730 \mathrm{~cm}^{-1}$, $1600 \mathrm{~cm}^{-1}$, and $1029 \mathrm{~cm}^{-1}$, respectively.

\section{Putative identification of metabolites in Andrographis paniculata}

The putative identification of metabolites in $A$ paniculata extract using UHPLC-Q-Orbitrap-HRMS was detected as many as 28-32 metabolites from seven growth sites (Table 4). The identified metabolites belong to the phenolic acid group, diterpene lactones, and flavonoids. Three phenolic acid compounds were identified in $A$. paniculata extract, namely cinnamic acid, caffeic acid, and 3-O-caffeoylquinic acid (Table 4). Cinnamic acid and caffeic acid are phenolic acids that produce fragmentation by releasing $\mathrm{H}_{2} \mathrm{O}$ and $\mathrm{COOH}$ molecules, namely at $\mathrm{m} / \mathrm{z}$ $149 \rightarrow 131 \rightarrow 105$ and $181 \rightarrow 163 \rightarrow 136$.

Diterpene lactones are the main class of compounds present in A. paniculata. In this study, we managed to identify as many as 15 terpene compounds of the lactone group, as shown in Table 4. Of the several metabolites belonging to the terpene lactone class, andrographolide is the main characteristic compound in A. paniculata. Andrographolide with m/z 351 (Rafi et al. 2021) was identified through detection of fragments with $\mathrm{m} / \mathrm{z} 333[\mathrm{M}$ $\left.+\mathrm{H}-\mathrm{H}_{2} \mathrm{O}\right]^{+}, 315\left[\mathrm{M}+\mathrm{H}-2 \mathrm{H}_{2} \mathrm{O}\right]^{+}, 297\left[\mathrm{M}+\mathrm{H}-3 \mathrm{H}_{2} \mathrm{O}\right]^{+}, 285$ $\left[\mathrm{M}+\mathrm{H}-2 \mathrm{H}_{2} \mathrm{O}-12\right]^{+}$, and $257\left[\mathrm{M}+\mathrm{H}-2 \mathrm{H}_{2} \mathrm{O}-12-28\right]^{+}$. This compound is the most dominant in the diterpene lactone group and has a high abundance, especially in the leaves (Komalasari and Harimurti 2015). Andrographolide is also a compound that plays an important role in biological activity as an antidiabetic (Nugroho et al. 2012).

Apart from phenolic acid and diterpene lactones, $A$. paniculata also has several flavonoid compounds (Gan et al. 2019; Rafi et al. 2021). A total of 14 flavonoid compounds were identified in the samples used, such as apigenin, luteolin, methoxy flavone derivatives, and andrographidin A. Quantitatively, the relative content of 32 metabolites from seven regions is shown in Figure 3. The andrographolide content (18) of A. paniculata samples in each area is relatively the same, while the 14-Deoxyandrographolide content is higher in the AP3 and AP5 regions.
Tabel 2. Yield of extracts, and $\mathrm{IC}_{50}$ of $\alpha$-glucosidase inhibitory activity of Andrographis paniculata extracts

\begin{tabular}{lcccc}
\hline \multirow{2}{*}{ Code of sample } & \multicolumn{2}{c}{ Yield $(\%)$} & \multicolumn{2}{c}{$\mathbf{I C}_{\mathbf{5 0}}(\mathbf{m g} / \mathbf{m L})(\mathbf{n}=\mathbf{3})$} \\
\cline { 2 - 5 } & EtOH & Water & EtOH & Water \\
\hline AP1 & 14.97 & 12.20 & $6.56 \pm 0.22^{\mathrm{a}}$ & $13.86 \pm 0.23^{\mathrm{b}}$ \\
AP2 & 13.84 & 11.47 & $8.58 \pm 0.22^{\mathrm{a}}$ & $12.65 \pm 0.46^{\mathrm{b}}$ \\
AP3 & 14.21 & 11.58 & $8.24 \pm 0.44^{\mathrm{a}}$ & $11.82 \pm 0.72^{\mathrm{b}}$ \\
AP4 & 14.63 & 12.15 & $8.77 \pm 0.23^{\mathrm{a}}$ & $11.55 \pm 0.17^{\mathrm{b}}$ \\
AP5 & 14.02 & 12.01 & $9.11 \pm 0.34^{\mathrm{a}}$ & $25.39 \pm 3.03^{\mathrm{b}}$ \\
AP6 & 13.77 & 11.23 & $9.21 \pm 0.27^{\mathrm{a}}$ & $12.09 \pm 0.07^{\mathrm{b}}$ \\
AP7 & 13.91 & 11.68 & $6.56 \pm 0.24^{\mathrm{a}}$ & $13.17 \pm 0.64^{\mathrm{b}}$ \\
Acarbose & & & $3.89 \pm 0.20^{\mathrm{a}}$ & \\
Andrographolide & \multicolumn{3}{c}{$7.22 \pm 0.33^{\mathrm{a}}$} \\
\hline
\end{tabular}

Note: The mean \pm SD within each measurement in the same column, followed with different lowercase letters, represents significant differences at $\mathrm{p}<0.05$.

Tabel 3. Functional group detected in Andrographis paniculata extracts

\begin{tabular}{ll}
\hline Wavenumber $\left(\mathbf{c m}^{-1}\right)$ & Functional group \\
\hline $3320-3300$ & O-H (stretching vibration) \\
$2919-2910$ & C-H sp ${ }^{3}$ (stretching vibration) \\
$2851-2849$ & C-H aldehyde (stretching vibration) \\
1733 & $\mathrm{C}=\mathrm{O}$ (stretching vibration) \\
$1611-1600$ & aromatic C=C (stretching vibration) \\
1415 & C-H sp ${ }^{3}$ (bending vibration) \\
$1232-1220$ & C-O ether (stretching vibration) \\
1029 & C-OH alcohol ( (stretching vibration) \\
$900-888$ & C-H alkene (bending vibration) \\
\hline
\end{tabular}

\section{Clustering of Andrographis paniculata}

Andrographis paniculata taken from several locations on the island of Java, Indonesia, has an FTIR spectrum fingerprint profile and a UHPLC-Q-Orbitrap HRMS chromatogram similar to one another. The only difference lies in the level of metabolite concentration detected. Therefore, in grouping samples based on their growth locations, chemometric analysis is needed, such as principal component analysis (PCA). PCA itself can simplify variables by reducing dimensions and providing an overview of sample grouping through the main component (PC) (Theodoridis et al. 2012). In this study, the two models of PCA was created using the absorption value of functional groups at a wavelength of 4000-650 $\mathrm{cm}^{-1}$ and the compounds' peak area values identified as variables.

Plot scores were generated from PCA analysis of $A$. paniculata extract with FTIR spectrum data (Figure 4A) and metabolite peak area (Figure 4B) as variables. The two score plots show the extract group based on the location of the growth. In the PCA score plot using FTIR spectra, we used three PC resulted in a three-dimensional score plot with the cumulative percentage of the three PCs used were $83 \%$. While for the PCA score plot using UHPLC chromatogram, we used two PCs that accounted for $93 \%$ of the cumulative percentage of the two PCs. Using FTIR spectrum data does not produce a good enough grouping than metabolite compound data, which means that each sample from each region cannot be appropriately distinguished only by FTIR spectrum fingerprint data. 
Tabel 4. Putative identification of metabolites in Andrographis paniculata from several locations of growth

\begin{tabular}{|c|c|c|c|c|c|c|c|c|c|c|c|}
\hline Senyawa & Mw & $\begin{array}{l}\text { Error } \\
(\mathbf{p p m})\end{array}$ & MS \& MS/MS & Formula & AP1 & AP2 & AP3 & AP4 & AP5 & AP6 & AP7 \\
\hline 3-O-Caffeoylquinic acid & 354.09502 & -0.17 & 355,163 & $\mathrm{C}_{16} \mathrm{H}_{18} \mathrm{O}_{9}$ & $\checkmark$ & $\checkmark$ & $\checkmark$ & $\checkmark$ & $\checkmark$ & $\checkmark$ & $\checkmark$ \\
\hline Cinnamic acid & 148.05241 & -0.13 & $149,131,105$ & $\mathrm{C}_{9} \mathrm{H}_{8} \mathrm{O}_{2}$ & $\checkmark$ & $\checkmark$ & $\checkmark$ & $\checkmark$ & $\checkmark$ & $\checkmark$ & $\checkmark$ \\
\hline Caffeic acid & 180.04243 & 0.95 & $181,163,136$ & $\mathrm{C}_{9} \mathrm{H}_{8} \mathrm{O}_{4}$ & $\checkmark$ & $\checkmark$ & $\checkmark$ & $\checkmark$ & $\checkmark$ & $\checkmark$ & $\checkmark$ \\
\hline 3-O- $\beta$-D-Glucopyranosyl andrographolide & 512.26133 & -1.60 & $513,351,333,315,297,285,257$ & $\mathrm{C}_{26} \mathrm{H}_{40} \mathrm{O}_{10}$ & $\checkmark$ & $\checkmark$ & $\checkmark$ & $\checkmark$ & $\checkmark$ & $\checkmark$ & $\checkmark$ \\
\hline Apigenin & 270.05214 & -2.53 & $271,153,119$ & $\mathrm{C}_{15} \mathrm{H}_{10} \mathrm{O}_{5}$ & $\checkmark$ & $\checkmark$ & $\checkmark$ & $\checkmark$ & $\checkmark$ & $\checkmark$ & $\checkmark$ \\
\hline 12S-Hydroxy andrographolide & 368.2197 & -0.51 & $369,351,333,315,297,285,257$ & $\mathrm{C}_{20} \mathrm{H}_{32} \mathrm{O}_{6}$ & $\checkmark$ & $\checkmark$ & $\checkmark$ & $\checkmark$ & $\checkmark$ & $\checkmark$ & $\checkmark$ \\
\hline Paniculide B & 280.13095 & -0.44 & $281,263,245,217$ & $\mathrm{C}_{15} \mathrm{H}_{20} \mathrm{O}_{5}$ & $\checkmark$ & $\checkmark$ & $\checkmark$ & $\checkmark$ & $\checkmark$ & $\checkmark$ & $\checkmark$ \\
\hline 5,7-Dihydroxy-8-methoxyflavone & 284.06819 & -0.99 & 285,119 & $\mathrm{C}_{16} \mathrm{H}_{12} \mathrm{O}_{5}$ & $\checkmark$ & $\checkmark$ & $\checkmark$ & $\checkmark$ & $\checkmark$ & $\checkmark$ & $\checkmark$ \\
\hline Apigenin-7-O-beta-D-glucuronide & 446.12082 & 80.50 & 447,271 & $\mathrm{C}_{22} \mathrm{H}_{22} \mathrm{O}_{10}$ & $\checkmark$ & $\checkmark$ & $\checkmark$ & $\checkmark$ & $\checkmark$ & $\checkmark$ & $\checkmark$ \\
\hline 5,4'-Dihidroxy-7,8,2',3'-tetramethoxyflavone & 374.09998 & -0.50 & $375,360,342$ & $\mathrm{C}_{19} \mathrm{H}_{18} \mathrm{O}_{8}$ & - & $\checkmark$ & $\checkmark$ & $\checkmark$ & $\checkmark$ & $\checkmark$ & $\checkmark$ \\
\hline Luteolin & 286.04656 & -4.12 & 287 & $\mathrm{C}_{15} \mathrm{H}_{10} \mathrm{O}_{6}$ & $\checkmark$ & $\checkmark$ & $\checkmark$ & $\checkmark$ & $\checkmark$ & $\checkmark$ & $\checkmark$ \\
\hline 14-Deoxy-17-hydroxy-andrographolide & 352.22466 & -0.89 & $353,335,317,299,287,259$ & $\mathrm{C}_{20} \mathrm{H}_{32} \mathrm{O}_{5}$ & $\checkmark$ & $\checkmark$ & $\checkmark$ & $\checkmark$ & $\checkmark$ & $\checkmark$ & $\checkmark$ \\
\hline 5-Hydroxy-7,8,2'-trimethoxyflavone 5-glucoside & 490.14757 & 0.12 & 491,329 & $\mathrm{C}_{24} \mathrm{H}_{26} \mathrm{O}_{11}$ & $\checkmark$ & $\checkmark$ & $\checkmark$ & $\checkmark$ & $\checkmark$ & $\checkmark$ & $\checkmark$ \\
\hline Paniculide C & 278.11549 & 0.24 & 279,261 & $\mathrm{C}_{15} \mathrm{H}_{18} \mathrm{O}_{5}$ & - & $\checkmark$ & $\checkmark$ & $\checkmark$ & - & $\checkmark$ & $\checkmark$ \\
\hline 5,4'-dihydroxy-7,8-dimethoxyflavone & 314.07876 & -0.88 & $315,197,119$ & $\mathrm{C}_{17} \mathrm{H}_{14} \mathrm{O}_{6}$ & $\checkmark$ & $\checkmark$ & $\checkmark$ & $\checkmark$ & $\checkmark$ & $\checkmark$ & $\checkmark$ \\
\hline Andrographic acid & 364.18871 & 0.33 & 365 & $\mathrm{C}_{20} \mathrm{H}_{28} \mathrm{O}_{6}$ & - & $\checkmark$ & $\checkmark$ & $\checkmark$ & $\checkmark$ & $\checkmark$ & - \\
\hline 14-deoxy-andrographiside & 496.26592 & -2.62 & $497,317,299,287,259$ & $\mathrm{C}_{26} \mathrm{H}_{40} \mathrm{O}_{9}$ & $\checkmark$ & $\checkmark$ & $\checkmark$ & $\checkmark$ & $\checkmark$ & $\checkmark$ & $\checkmark$ \\
\hline Andrographolide & 350.20816 & -3.32 & $351,297,285,257$ & $\mathrm{C}_{20} \mathrm{H}_{30} \mathrm{O}_{5}$ & $\checkmark$ & $\checkmark$ & $\checkmark$ & $\checkmark$ & $\checkmark$ & $\checkmark$ & $\checkmark$ \\
\hline Apigenin 7,4'-dimethyl ether & 298.08378 & -1.21 & 299,133 & $\mathrm{C}_{17} \mathrm{H}_{14} \mathrm{O}_{5}$ & $\checkmark$ & $\checkmark$ & $\checkmark$ & $\checkmark$ & $\checkmark$ & $\checkmark$ & $\checkmark$ \\
\hline 5-Hydroxy-7,8-dimethoxyflavanone & 300.09918 & -2.07 & $301,197,105$ & $\mathrm{C}_{17} \mathrm{H}_{16} \mathrm{O}_{5}$ & $\checkmark$ & $\checkmark$ & $\checkmark$ & $\checkmark$ & $\checkmark$ & $\checkmark$ & $\checkmark$ \\
\hline Andrographidin A & 462.15198 & -1.33 & $463,301,197$ & $\mathrm{C}_{23} \mathrm{H}_{26} \mathrm{O}_{10}$ & $\checkmark$ & $\checkmark$ & $\checkmark$ & $\checkmark$ & $\checkmark$ & $\checkmark$ & $\checkmark$ \\
\hline 5-Hydroxy-7,2',6'-trimethoxyflavone & 328.09435 & -1.03 & $329,314,299$ & $\mathrm{C}_{18} \mathrm{H}_{16} \mathrm{O}_{6}$ & $\checkmark$ & $\checkmark$ & $\checkmark$ & $\checkmark$ & $\checkmark$ & $\checkmark$ & $\checkmark$ \\
\hline 5-Hydroxy-3,7,8,2'-tetramethoxyflavone & 358.10486 & -1.09 & $359,329,197$ & $\mathrm{C}_{19} \mathrm{H}_{18} \mathrm{O}_{7}$ & $\checkmark$ & $\checkmark$ & $\checkmark$ & - & - & $\checkmark$ & $\checkmark$ \\
\hline Neoandrographolide & 480.27237 & 0.11 & 481 & $\mathrm{C}_{26} \mathrm{H}_{40} \mathrm{O}_{8}$ & $\checkmark$ & $\checkmark$ & $\checkmark$ & - & - & - & - \\
\hline 14-Acetyl-andrographolide & 392.22 & -0.28 & $393,315,297,285,257$ & $\mathrm{C}_{22} \mathrm{H}_{32} \mathrm{O}_{6}$ & $\checkmark$ & $\checkmark$ & $\checkmark$ & $\checkmark$ & $\checkmark$ & $\checkmark$ & $\checkmark$ \\
\hline Andrograpanin & 318.2187 & -2.50 & $319,301,289,261$ & $\mathrm{C}_{20} \mathrm{H}_{30} \mathrm{O}_{3}$ & $\checkmark$ & $\checkmark$ & $\checkmark$ & $\checkmark$ & $\checkmark$ & $\checkmark$ & $\checkmark$ \\
\hline 14-Deoxy-11-oxoandrographolide & 348.1936 & -0.21 & $349,331,313,285$ & $\mathrm{C}_{20} \mathrm{H}_{28} \mathrm{O}_{5}$ & - & - & $\checkmark$ & - & - & - & - \\
\hline 14-Deoxy-andrographolide & 334.2134 & -3.02 & $335,317,299,287$ & $\mathrm{C}_{20} \mathrm{H}_{30} \mathrm{O}_{4}$ & $\checkmark$ & $\checkmark$ & $\checkmark$ & $\checkmark$ & $\checkmark$ & $\checkmark$ & $\checkmark$ \\
\hline Andrographolactone & 296.1769 & -2.46 & 297,269 & $\mathrm{C}_{20} \mathrm{H}_{24} \mathrm{O}_{2}$ & $\checkmark$ & $\checkmark$ & $\checkmark$ & $\checkmark$ & $\checkmark$ & $\checkmark$ & $\checkmark$ \\
\hline Dehydro-andrographolide & 332.1977 & -3.19 & $333,315,297,285,257$ & $\mathrm{C}_{20} \mathrm{H}_{28} \mathrm{O}_{4}$ & $\checkmark$ & $\checkmark$ & $\checkmark$ & $\checkmark$ & $\checkmark$ & $\checkmark$ & $\checkmark$ \\
\hline $5,7,2^{\prime}, 3^{\prime}$-Tetramethoxy-flavanone & 344.1259 & -0.29 & 345 & $\mathrm{C}_{19} \mathrm{H}_{20} \mathrm{O}_{6}$ & $\checkmark$ & $\checkmark$ & $\checkmark$ & $\checkmark$ & $\checkmark$ & $\checkmark$ & $\checkmark$ \\
\hline Dihydroskullcap-flavone I & 316.0945 & -0.59 & $317,299,197,121$ & $\mathrm{C}_{17} \mathrm{H}_{16} \mathrm{O}_{6}$ & $\checkmark$ & $\checkmark$ & $\checkmark$ & $\checkmark$ & $\checkmark$ & $\checkmark$ & $\checkmark$ \\
\hline
\end{tabular}




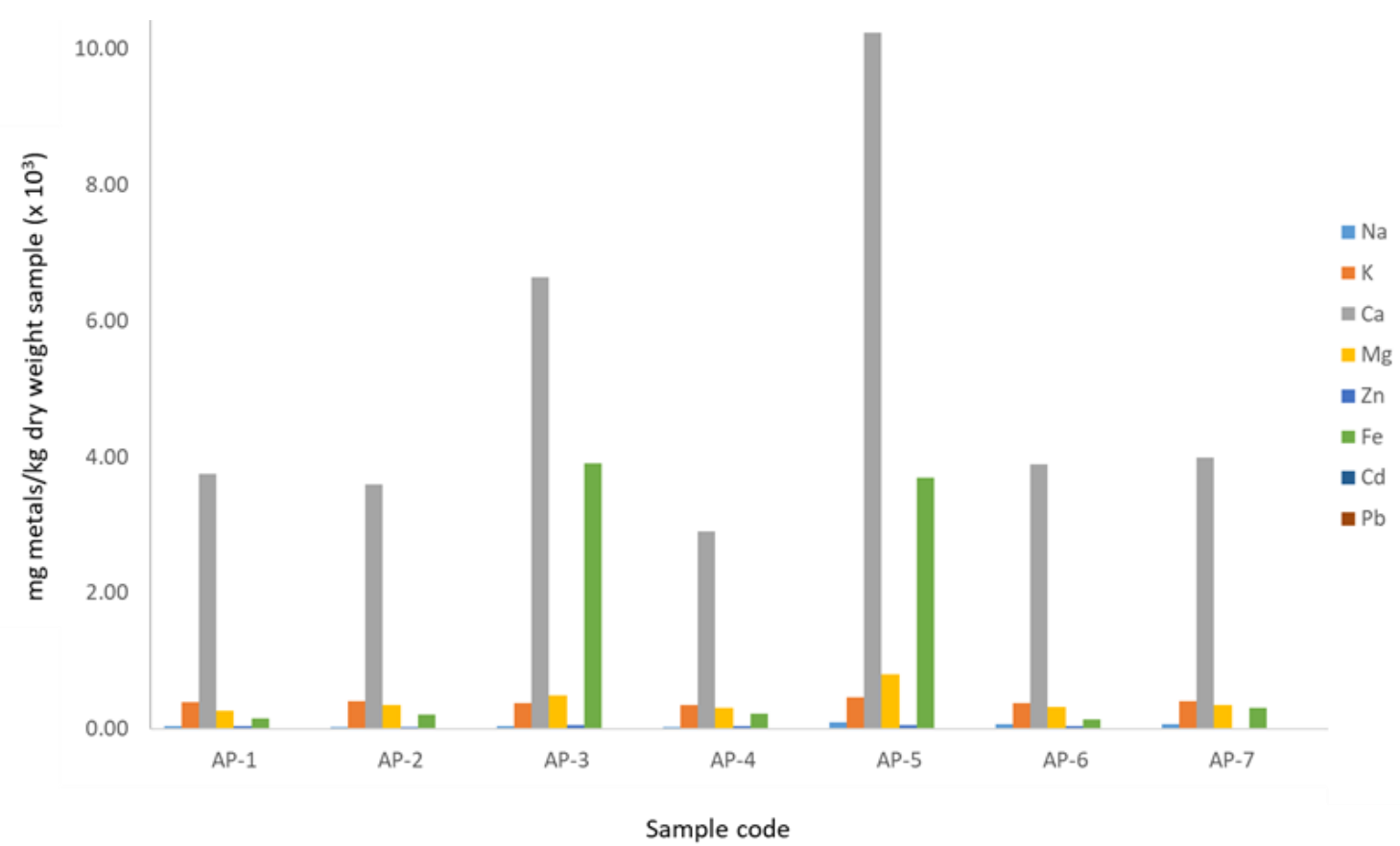

Figure 1. Metals composition and level in Andrographis paniculata

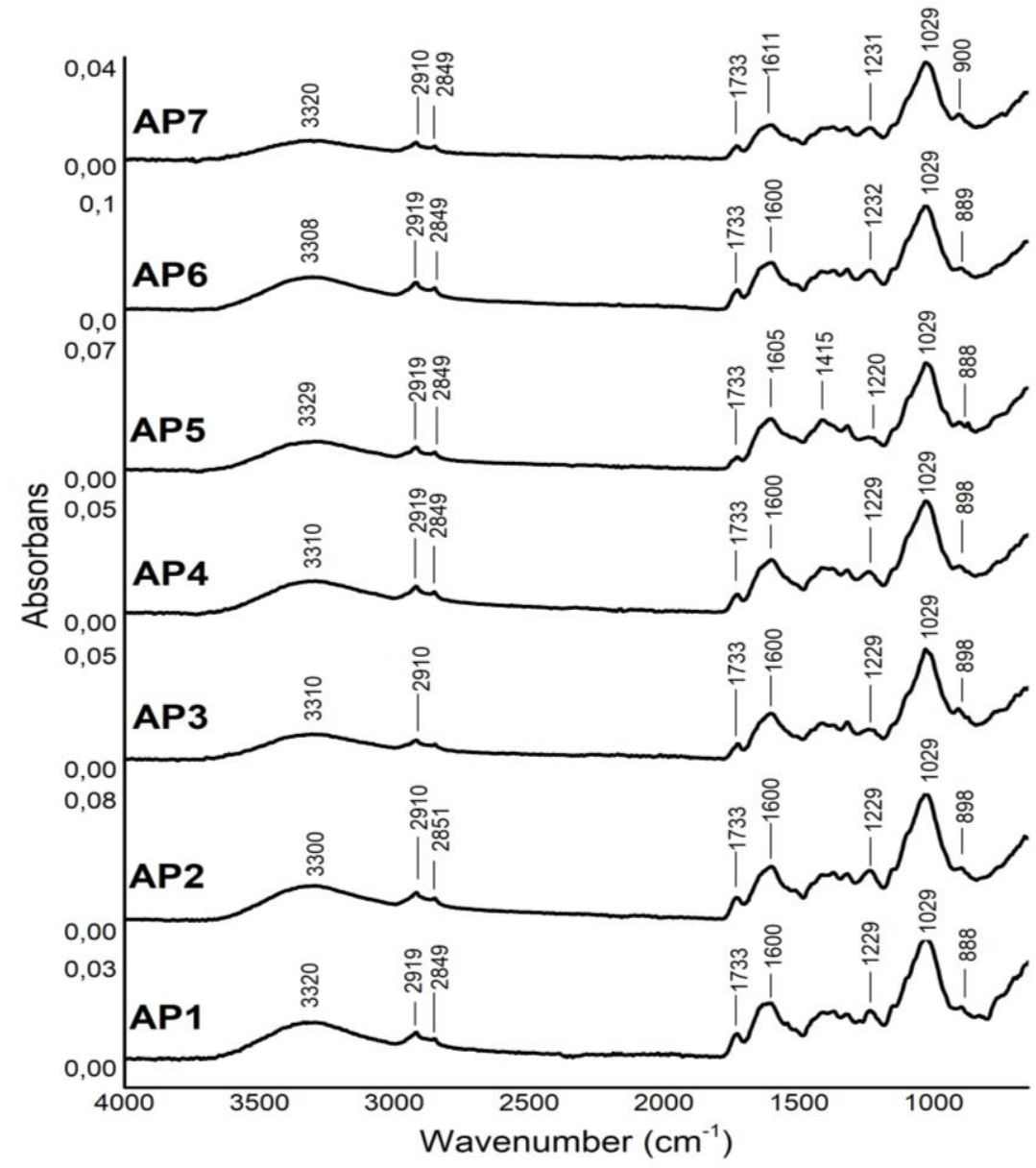

Figure 2. FTIR spectrum pattern of Andrographis paniculata from various sampling locations 


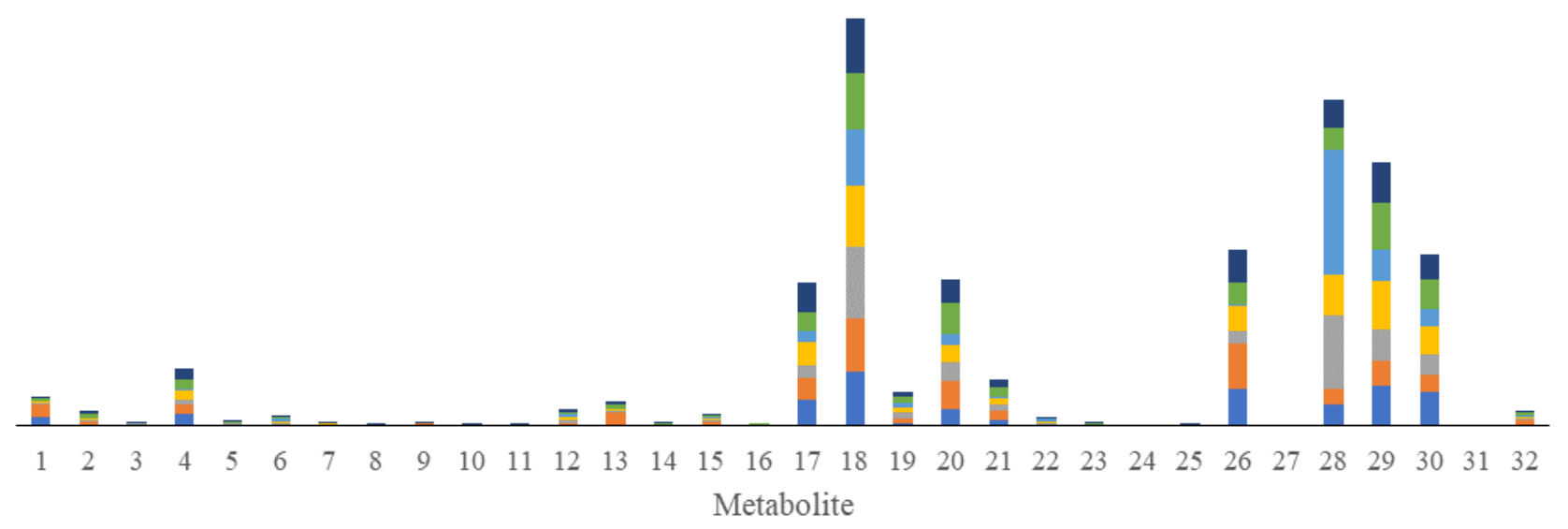

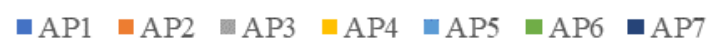

Figure 3. Relative amount of metabolites present in Andrographis paniculata from seven locations of growth

Scores

A
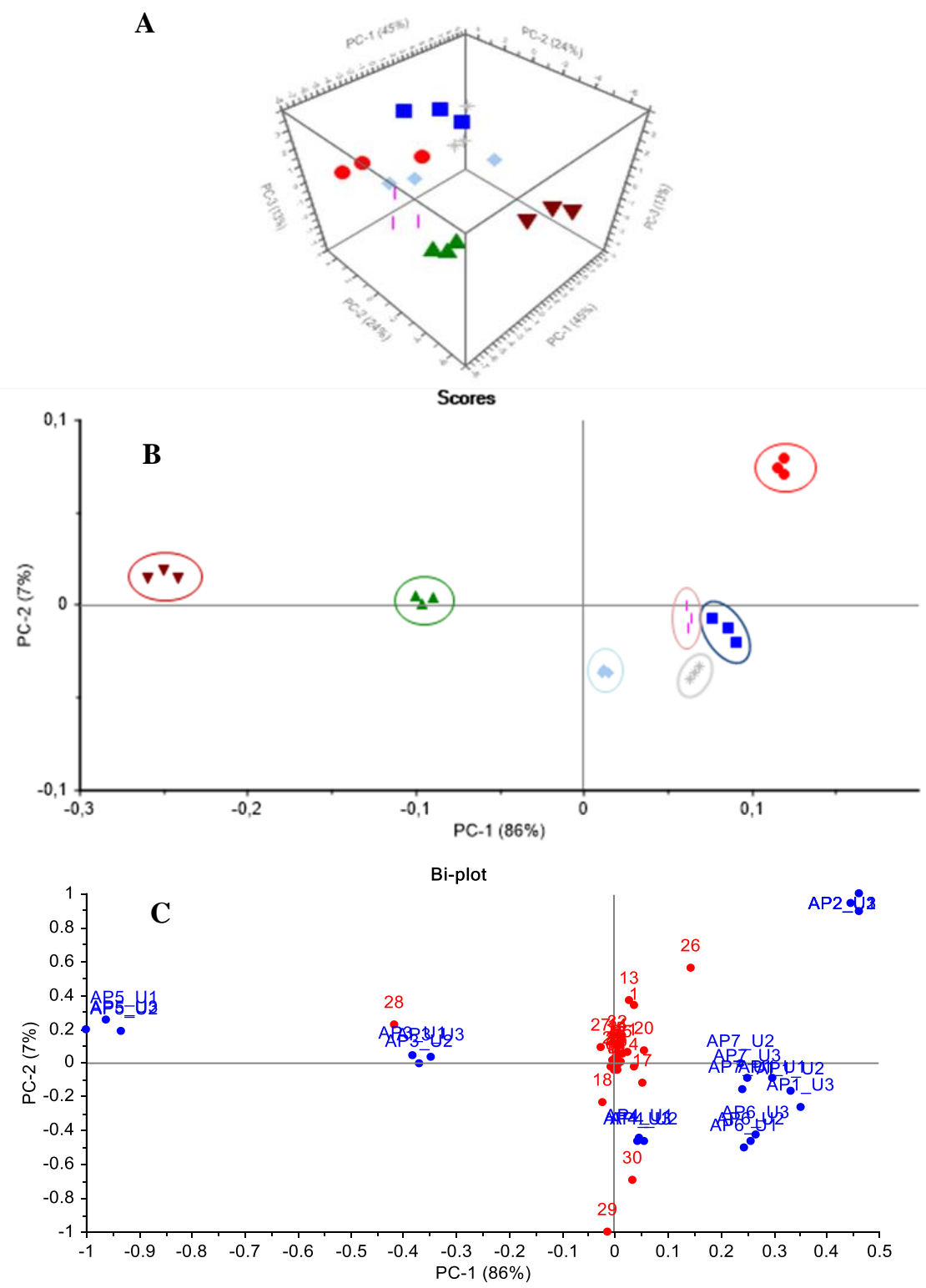

Figure 4. PCA score plot of FTIR spectra in 3D (A), PCA socre plot (B) and and biplot (C) of 32 identified metabolites in 2D. AP1 ( $\square$ ), $\operatorname{AP2}(\boldsymbol{\bullet}), \operatorname{AP3}(\boldsymbol{\Delta}), \operatorname{AP4}(>), \operatorname{AP5}(\boldsymbol{\nabla}), \operatorname{AP6}(-)$, dan AP7 () 
Groups close together to show a high similarity of metabolite profiles, while samples with different metabolite profiles will form distant groups. Figure $4 \mathrm{C}$ is a combination of the score plot and loading plot (biplot) to show the metabolite that contributes to the separation of A. paniculata according to its geographical origin. Separation of AP5 and AP3 from other groups was influenced by 14deoxy-andrographolide, while for AP2 because of andrograpanin compound. Dehydroandrographolide is responsible for the separation of AP1, AP4, AP6, and AP7.

In conclusion, Andrographis paniculata extract from seven locations of growth has different $\alpha$-glucosidase inhibitory activity and metals composition. Ethanolic extract of $A$. paniculata showed more significant inhibition of $\alpha$-glucosidase activity compared to water extract. Calcium was found more abundant in A. paniculata than other metals determined in this study. FTIR spectrum and UHPLC-Q-Orbitrap HRMS chromatogram of $A$. paniculata showed a similar profile and only differed in their metabolites intensity. We found A. paniculata extract have $\mathrm{OH}, \mathrm{C}=\mathrm{O}, \mathrm{C}=\mathrm{C}$ aromatic, and $\mathrm{C}-\mathrm{O}$ functional group from the FTIR spectra obtained. About 32 metabolites were putatively identified in A. paniculata, mainly come from phenolic and diterpene lactone class compounds. Clustering A. paniculata based on geographical origin was achieved using FTIR spectra and peak area from 32 identified peaks. Based on the result obtained, we found that the growth location affected the metals and metabolite's composition and level, resulting in different levels of $\alpha$-glucosidase inhibitory activity.

\section{ACKNOWLEDGEMENTS}

The authors gratefully acknowledged the Ministry of Research, Technology, and Higher Education of the Republic of Indonesia through the World Class University Program of IPB University for financial support of this research by Riset Kolaborasi Indonesia Grant 2019 (No.: 0847/IT3.L1/PN/2019).

\section{REFERENCES}

Aneesh A, George AJ, Kariyil BJ, Khrisna D, Sajitha IS. 2018. Phytochemical evaluation of Andrographis paniculata L. (L.). J Pharmacogn Phytochem 7 (4): 1949-1953.

Awin T, Mediani A, Maulidiani, Shaari K, Faudzi SMM, Sukari MAH, Lajis NH, Abas F. 2016. Phytochemical profiles and biological activities of Curcuma species subjected to different drying methods and solvent systems: NMR-based metabolomics approach. Industr Crops Prod 94: 342-352. DOI: 10.1016/j.indcrop.2016.08.020.

Aziz Z, Yuliana ND, Simanjuntak P, Rafi M, Abdillah S. 2020. FTIR and HPLC-based metabolomics of yacon leaves extracts (Smallanthus sonchifolius [Poepp \& Endl.] H. Robinson) from two locations in Indonesia. Indon J Chem 20 (3): 567-578. DOI: 10.22146/ijc.43453.

Borges CV, Minatel IO, Gomez-Gomez HA, Lima GPP. 2017. Medicinal plants: Influence of environmental factors on the content of secondary metabolites. In: Ghorbanpour M, Varma A. (eds) Medicinal Plants and Environmental Challenges. Cham, Springer International Publishing AG, Berlin. DOI: 10.1007/978-3-319-68717-9_15.

Brinckmann JA. 2013. Emerging importance of geographical indications and designations of origin-authenticating geo-authentic botanicals and implications for phytotherapy. Phytother Res 27: 1581-1587. DOI: $10.1002 /$ ptr.4912.

Bunaciu AA, Aboul-Enein HY, Fleschin S. 2011. Recent applications of Fourier transform infrared spectrophotometry in herbal medicines analysis. Appl Spectrosc Rev 46: 251-260. DOI: 10.1080/05704928.2011.565532.

Chua LS, Yap KC, Jaganath IB. 2013. Comparison of total phenolic content, scavenging activity and HPLC-ESI-MS/MS profiles of both young and mature leaves and stems of Andrographis paniculata. Nat Prod Commun 8 (12): 1725-1729. DOI: 10.1177/1934578X1300801217.

Gan L, Zheng Y, Deng L, et al. 2019. Diterpenoid Lactones with AntiInflammatory Effects from the Aerial Parts of Andrographis paniculata. Molecules 24 (15): 2726. DOI: 10.3390/molecules24152726

Khattak KF, Rahman T. 2015. Effect of geographical distributions on nutrient composition, phytochemical profile, and antioxidant activity of Morus nigra. Pakistan J Pharmaceut Sci 28 (5): 1671-1678.

Komalasari T, Harimurti S. 2015. A review on the antidiabetic activity of Andrographis paniculata (Burm. f.) Nees based in-vivo study. International J Public Health Sci 4 (4): 256-263. DOI: 10.11591/.v4i4.4743.

Maria MFF, Ikhmal WMKWM, Sabri MGM, Ibrahim MSC, Adnan A. 2018. Identification of functional group present in Andrographis paniculata (Kalmegh) leaves by FTIR analysis. IOP Conf Ser Materi Sci Eng 440: 012035. DOI: 10.1088/1757-899X/440/1/012035.

Mythili S, Sowmya V, Sathia VA. 2011. Analysis of heavy metal content in Andrographis paniculata. International J Pharmaceuti Sci Rev Res 10 (1): 165-166.

Nugroho AE, Andrie M, Warditiani NK, Siswanto E, Pramono S, Lukitaningsih E. 2012. Antidiabetic and antihiperlipidemic effect of Andrographis paniculata (Burm. f.) Nees and andrographolidein highfructose-fat-fed rats. Indian J Pharmacol 44 (3): 377-381. DOI: 10.4103/0253-7613.96343.

Rafi M, Devi AF, Syafitri UD, Heryanto R, Suparto IH, Amran MB, Rohman A, Prajogo B, Lim LW. 2020a. Classification of Andrographis paniculata extracts by solvent extraction using HPLC fingerprint and chemometric analysis. BMC Res Notes 13: 56. DOI: 10.1186/s13104-020-4920-x.

Rafi M, Karomah AH, Heryanto R, Septaningsih DA, Kusuma WA, Amran MB, Rohman A, Prajogo B. 2020b. Metabolite profiling of Andrographis paniculata leaves and stem extract using UHPLC-Orbitrap-MS/MS. Nat Prod Res. DOI: 10.1080/14786419.2020.1789637.

Sampaio BL, Ebel RE, Costa FBD. 2016. Effect of environment on the secondary metabolic profile of Tithonia diversifolia: a model for environmental metabolomics of plants. Sci Rep 6: 29265. DOI: $10.1038 /$ srep29265.

Song YX, Liu SP, Jin Z, Qin JF, Jiang ZY. 2013. Qualitative and quantitative analysis of Andrographis paniculata by rapid resolution liquid chromatography/time-of-flight mass spectrometry. Molecules 18 (10): 12192-12207. DOI: 10.3390/molecules181012192.

Subramanian R, Asmawi MZ, Sadikun A. 2008. In vitro alpha-glucosidase and alpha-amylase enzyme inhibitory effects of Andrographis paniculata extract and andrographolide. Acta Biochimica Polonica 55 (2): 391-398.

Theodoridis GA, Gika HG, Want EJ, Wilson ID. 2012. Liquid chromatography-mass spectrometry-based global metabolite profiling: a review. Analytica Chimica Acta 711: 7-16. DOI: 10.1016/j.aca.2011.09.042.

Umar AH, Ratnadewi D, Rafi M, Sulistyaningsih YC. 2021. Untargeted metabolomics analysis using FTIR and UHPLC-Q-Orbitrap HRMS of two curculigo species and evaluation of their antioxidant and $\alpha$-glucosidase inhibitory activities. Metabolites 11 (1): 42. DOI: 10.3390/metabo11010042.

van der Kooy F, Maltese F, Choi YH, Kim HK, Verpoorte R. 2009. Quality control of herbal material and phytopharmaceuticals with MS and NMR based metabolic fingerprinting. Planta Medica 75 (7):763-775. DOI: 10.1055/s-0029-1185450.

Yusof NA, Isha A, Ismail IS, Khatib A, Shaari K, Abas F, Rukayadi Y. 2015. Infrared-metabolomics approach in detecting change in Andrographis paniculata metabolites due to different harvesting ages and times. J Sci Food Agric 95 (12): 2533-2543. DOI: 10.1002/jsfa.6987.

Xiao JF, Zhou B, Ressom HW. 2012. Metabolite identification and quantitation in LC-MS/MS-based metabolomics. Trends Anal Chem 32: 1-14. DOI: 10.1016/j.trac.2011.08.009.

Zantar S, Garrouj DE, Pagan R, Chabi M, Laglaoui A, Bakkali M, Zerrouk MH. 2015. Effect on harvest time on yield, chemical composition, antimicrobial and antioxidant activities of Thymus vulgaris and Mentha pulegium essential oil. Eur J Med Plants 8 (2): 69-77. DOI: 10.9734/EJMP/2015/17513. 